\title{
Strain localization in ultramylonitic marbles by simultaneous activation of dislocation motion and grain boundary sliding (Syros, Greece)
}

\author{
A. Rogowitz ${ }^{1,2}$, J. C. White ${ }^{3}$, and B. Grasemann ${ }^{1}$ \\ ${ }^{1}$ Department for Geodynamics and Sedimentology, University of Vienna, Althanstrasse 14, 1090 Vienna, Austria \\ ${ }^{2}$ Natural History Museum, Burgring 7, 1010 Vienna, Austria \\ ${ }^{3}$ Department of Earth Sciences, University of New Brunswick, 3 Bailey Dr, Fredericton, NB E3B 5A3, Canada
}

Correspondence to: A. Rogowitz (anna.rogowitz@univie.ac.at)

Received: 9 August 2015 - Published in Solid Earth Discuss.: 18 September 2015

Revised: 15 February 2016 - Accepted: 20 February 2016 - Published: 8 March 2016

\begin{abstract}
Extreme strain localization occurred in the centre of the cross-cutting element of a flanking structure in almost pure calcite marbles from Syros, Greece. At the maximum displacement of $120 \mathrm{~cm}$ along the cross-cutting element, evidence of grain size sensitive deformation mechanisms can be found in the ultramylonitic marbles, which are characterized by (1) an extremely small grain size $(\sim 3 \mu \mathrm{m})$, (2) grain boundary triple junctions with nearly $120^{\circ}$ angles, (3) a weak crystallographic preferred orientation with very low texture index $(J=1.4)$, (4) a random misorientation angle distribution curve and (5) the presence of small cavities. Using transmission electron microscopy, a deformation sequence is observed comprising recrystallization dominantly by bulging, resulting in the development of the fine-grained ultramylonite followed by the development of a high dislocation density $\left(\sim 10^{13} \mathrm{~m}^{-2}\right)$ with ongoing deformation of the fine-grained ultramylonite. The arrangement of dislocations in the extremely fine-grain-sized calcite differs from microstructures created by classical dislocation creep mediated by combined glide and thermally activated climb. Instead, it exhibits extensive glide and dislocation networks characteristic of recovery accommodated by cross-slip and network-assisted dislocation movement without formation of idealized subgrain walls. The enabling of grain boundary sliding to dislocation activity is deemed central to initiating and sustaining strain softening and is argued to be an important strain localization process in calcite rocks, even at a high strain rate $\left(\sim 10^{-9} \mathrm{~s}^{-1}\right)$ and low temperature $\left(300^{\circ} \mathrm{C}\right)$.
\end{abstract}

\section{Introduction}

Strain localization in monomineralic rocks when associated with brittle precursors can exhibit microstructural evolution comprising grain size reduction and ensuing activation of grain-size-sensitive (GSS) deformation mechanisms such as diffusion creep, cataclastic flow and independent grain boundary sliding (GBS) (Schmid, 1976; Schmid et al., 1977; Etheridge and Wilkie, 1979; Segall and Pollard, 1983; Pennacchioni and Mancktelow, 2007; Menegon et al., 2013). The aforementioned mechanisms are typically anticipated to result in a random crystallographic orientation or decrease in the intensity of any pre-existing texture formed during plastic deformation of the original material. However, reports of fine-grained deformed polycrystalline materials showing a crystallographic preferred orientation $(\mathrm{CPO})$ indicate that deformation mechanisms operative during GSS flow can develop a CPO (Schmid et al., 1977; Rutter et al., 1994; Barreiro et al., 2007; Sundberg and Cooper; 2008; Wang et al., 2010; Hansen et al., 2011; Kushnir et al., 2015).

GBS can contribute to non-uniform GSS flow behaviour (e.g. Ashby and Verall, 1973) and is able to support extremely high strains. Nevertheless, accommodation of relative grain displacement requires accommodation mechanisms to occur collaboratively in order to maintain reasonable strain compatibility. Maintenance of strain compatibility amongst grains requires grain boundary reorganization by diffusional flow and/or dislocation glide and climb within the grain boundary and the grain boundary region (Gifkins, 1976), with diffusion at relatively high homologous tem- 
perature being most commonly invoked (e.g. Boullier and Guéguen, 1975). More recently the simultaneous activity of dislocation creep and GBS has been inferred to be active in ultramylonites deformed both in nature (Vitale et al., 2007; Molli et al. 2011) and experimentally (Wang et al., 2010; Hansen et al., 2011; Kushnir et al., 2015).

The material under study is an essentially pure calcite marble layer from Syros (Cyclades, Greece). Previous work (Rogowitz et al., 2014) has established that the marble deformed under lower greenschist facies conditions, resulting in a grain size of $\sim 3 \mu \mathrm{m}$, well within the range for which deformation by GSS mechanisms is anticipated. For the observed grain size and deformation conditions, maximum strain rates of $\sim 10^{-9} \mathrm{~s}^{-1}$ have been determined (Rogowitz et al., 2014) using flow laws of Renner et al. (2002) and Herwegh et al. (2003). Therein lies a potential contradiction in that such strain rates at low temperatures point toward the operation of brittle deformation rather than ductile flow. In this contribution we present and discuss the microstructures of the calcite ultramylonite that address some of the aforementioned issues in deformed fine-grained rocks. Detailed analyses have been performed using optical microscopy, secondary electron microscopy (SEM), electron backscatter diffraction (EBSD) mapping and transmission electron microscopy (TEM) in order to elucidate the deformation mechanisms active at the given temperature, differential stress and strain rate conditions associated with this extreme strain localization.

\section{Geological setting and outcrop description}

The ultramylonite in question developed during formation of an a-type flanking structure in an almost pure calcite marble situated on Syros (35:00 UTM, $414840^{\circ}$ N, $313839^{\circ}$ E), which is one of the Cycladic islands that are located in the back arc of the Hellenic subduction zone (Papanikolauo, 1987; Wortel et al., 1993). The Cycladic area has been affected by two main metamorphic events: (1) an Eocene eclogite-blueschist metamorphic event and (2) an OligoMiocene greenschist facies event (Jolivet and Brun, 2010 and references cited therein). The rocks exposed on Syros mainly belong to the Cycladic blueschist unit, which is dominated by metagabbros, metabasites, metasediments and schists. Petrological studies (e.g. Trotet et al., 2001; Keiter et al., 2004) constrain the pressure-temperature evolution of rocks on Syros to peak conditions on the order of $1.8 \mathrm{GPa}$ and $550^{\circ} \mathrm{C}$. The greenschist facies overprint is assumed to encompass retrograde conditions around $300^{\circ} \mathrm{C}$ and 0.2 to 0.4 GPa (Trotet et al., 2001; Keiter et al., 2004; Schumacher et al., 2008). There is a general increase in greenschist facies overprint towards the SW of Syros attended by a NE-SWstretching lineation and a predominant top-to-the-east sense of shear (Keiter et al., 2004; Philippon et al., 2011; Rogowitz et al., 2015).
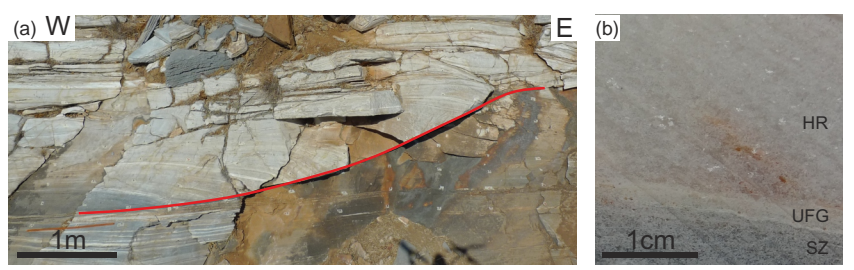

Figure 1. (a) Image presenting the studied flanking structure on Syros. The red line traces the cross-cutting element (i.e. shear zone). (b) Close-up of the boundary between the shear zone (SZ) and host rock (HR) showing a thin layer that is ultra-fine-grained (UFG) and white in appearance.

The pre-existing crack (cross-cutting element) associated with the flanking structure (Fig. 1a) was initially orientated at an angle of $90^{\circ}$ to the main foliation. During greenschist facies overprinting, rotation of the crack produced an antithetic (top-to-the-west) shear zone (Fig. 1a). A maximum displacement of $120 \mathrm{~cm}$ occurs in the centre of the shear zone where the initially coarse-grained, almost pure calcite marble has its grain size reduced to an extremely fine-grained ultramylonite (Fig. 2) with a white porcelaneous macroscopic appearance (Fig. 1b). The ultramylonitic layers have a total thickness of $0.12-0.48 \mathrm{~cm}$ and border the shear zone that comprises alternating protomylonitic and ultramylonitic calcite layers, with a total thickness of $1.5 \mathrm{~cm}$ (Rogowitz et al., 2014). Assuming that the marble deformed under simple shear conditions, the total strain at this locality is at least 80 . If it is assumed that most of the strain was accommodated by the fine-grained ultramylonite, a shear strain up to 1000 can be inferred as an upper limit (Rogowitz et al., 2014).

\section{Methods}

\subsection{Sample preparation}

Selected specimens of the shear zone were cut perpendicular to the shear zone boundary and parallel to the stretching lineation ( $x z$ plane of finite strain). Mechanically polished thin sections with a thickness between 20 and $30 \mu \mathrm{m}$ were prepared for microstructure analysis. Thin sections selected for SEM and EBSD analyses were chemo-mechanically polished with an alkaline colloidal silica suspension (Köstrosol, 3530; pH 9.2-10). To establish electric conductivity the thin sections were carbon coated. Additionally, hand specimens have been broken in approximately an $x z$ and $x y$ orientation of finite strain for grain boundary surface analysis by SEM. Specimens for TEM have been prepared by the focused ion beam (FIB) technique and standard argon ion beam thinning using a Gatan precision ion polishing system $\left(\right.$ PIPS $\left.^{\odot}\right)$.

In order to characterize microstructural development during progressive deformation of the fine-grained ultramylonitic layer, FIB foils were prepared along a profile across small calcite grains within the transition zone from coarser 

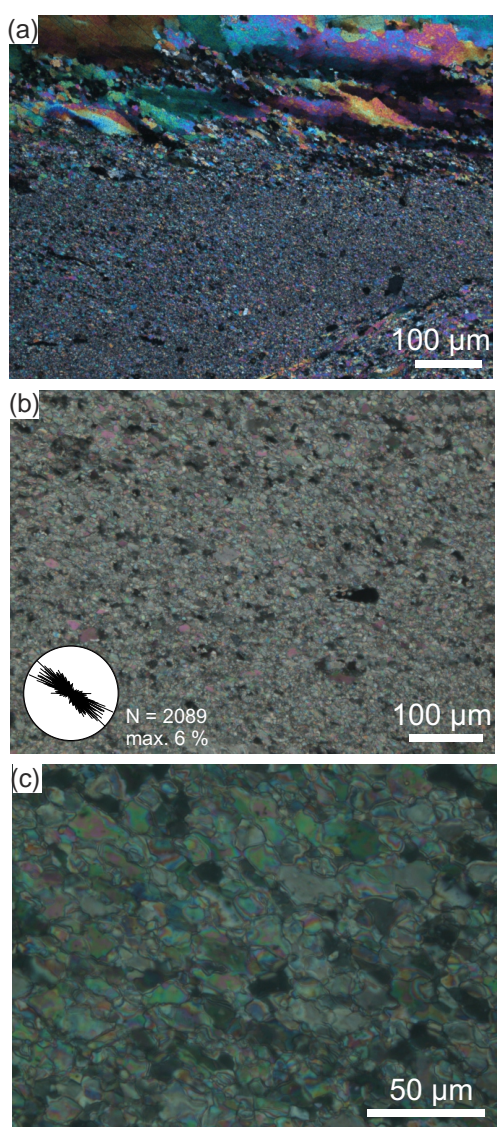

Figure 2. Optical micrographs of calcite marble (crossed polarizers). (a) Transition between host rock and fine-grained ultramylonite. Note the extreme grain size reduction. (b) Fine almost equigranular ultramylonite. The inserted sketch represents a rose diagram showing the 2-D orientation of the long axis of calcite grains. (c) Close-up of fine-grained ultramylonite. Note that grain boundaries of coarser grains are strongly curved compared to smaller grains.

grained marble to the fine-grained ultramylonite. This enabled comparison of the defect structure within newly developed grains and those that have been further deformed within the ultramylonite layer. For analysis of microstructures within the ultramylonitic calcite, FIB foils showing a profile over at least two grains have been prepared. PIPS ${ }^{\odot}$ was used to prepare specimens across comparable transitions in order to sample larger areas for comparison and integration with the FIB observations.

\subsection{Microfabric analysis}

A Leica DM4500 P optical microscope has been used for selecting appropriate thin sections for detailed microfabric analysis (Fig. 2). In order to visualize the presence of cracks, cavities and grain boundary surface character SEM was performed on a FEI Quanta 3-D FEG SEM equipped with an EDAX Pegasus Apex 4 system consisting of a Digiview IV
EBSD camera and an Apollo XV silicon drift detector for EDX spectrometry at the University of Vienna, Department of Lithospheric Research (Figs. 3, 5). Crystallographic orientations have been measured by combined EBSD mapping and EDX spectrometry (Fig. 4). The instrument was operated at a $10 \mathrm{kV}$ accelerating voltage, a $4 \mathrm{nA}$ probe current at working distances between 10 and $14 \mathrm{~mm}$. For EBSD analysis the sample was tilted up to an angle of $70^{\circ}$.

EBSD data were processed using the MATLAB $^{\odot}$ toolbox for quantitative texture analysis MTEX (Bachmann et al., 2010). Orientation distribution functions (ODFs) were calculated after Bunge (1982). The orientation of the $c$ (0001), $-a<11-20>, r\{0-14\}, f\{01-12\}, e\{01-18\}$ and $m$ $\{10-10\}$ poles were derived from the ODF and plotted as equal area lower hemisphere projections (Fig. 4a). Additionally, the misorientation-angle distributions for neighbourpair and random-pair grains have been determined and are represented together with the calculated theoretical, random misorientation-angle distribution for trigonal crystal symmetry (Fig. 4b; Mackenzie and Thompson, 1957).

TEM was performed with a JEOL 2011 STEM equipped with a double-tilt analytical holder and a Gatan MSC digital camera for imaging at the University of New Brunswick, Microscopy and Microanalysis Facility. The TEM was operated at an accelerating voltage of $200 \mathrm{kV}$ in bright- and dark-field modes (Figs. 6, 7).

\subsection{Dislocation density determination}

Dislocation densities were measured by use of the line-cut method. The number of intersections between dislocations and a prescribed grid of traverse lines was counted. The dislocation density $\rho$ was then determined using

$\rho=2 N / L t$,

with $t$ being the specimen thickness, $N$ the number of counted intersections and $L$ the total length of the used grid.

32 randomly chosen TEM bright field images were used in order to get a representative result. Dislocation densities were calculated for an average, maximum and minimum specimen thickness (Table S1 in Supplement).

\section{Results}

\subsection{Microfabric}

The Syros ultramylonitic marble is characterized by quasiequigranular to low aspect ratio fine-grained calcite, ranging in grain size from 1 to $10 \mu \mathrm{m}$, with an average of approximately $3 \mu \mathrm{m}$ (Figs. 2, 4d). Grains show a shape preferred orientation that is oblique to the main foliation, consistent with top-to-the-west non-coaxial displacement within the shear zone (Fig. 2b). Triple and four-grain junctions occur throughout the ultramylonite. Less common coarse relict grains have 

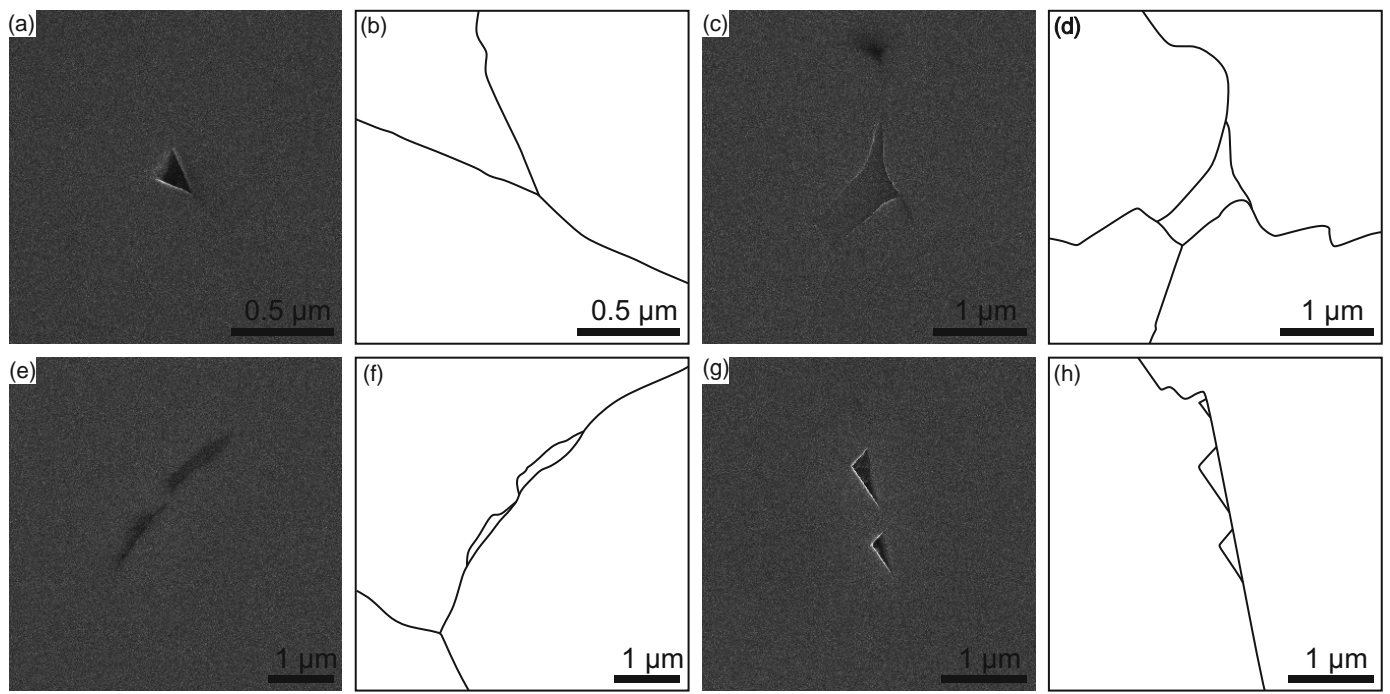

Figure 3. Secondary electron images showing preferred locality of cavities in fine-grained ultramylonite (a, c, e, g). The sketches represent grain boundary drawings of the areas, respectively $(\mathbf{b}, \mathbf{d}, \mathbf{f}, \mathbf{h})$. (a, b) Small cavity at grain boundary triple junction. (c, d) Cavity located at four-grain junction. (e, f) Grain boundary opening at grain boundary in extension. (g, h) Small cracks showing the same orientation, piling up at the grain boundary.

more curved grain boundaries, while small grains show crystal faces (Fig. 2c). In proximity to a coarser grained layer, a higher number of small grain boundary bulges connected to coarser, curved calcite grains can be observed. Small cavities with a size up to $1 \mu \mathrm{m}$ are located at grain-triple and four-grain junctions (Figs. 3a-d, 5c, d). Additionally, small, elongated grain boundary openings preferentially orientated at grain boundaries inferred to have been in extension can be observed (Fig. 3e, f). Small cracks orientated at approximately the same angle are observed to be concentrated at grain boundaries orientated at a high angle to the foliation (Fig. 3g, h, 5f).

Calcite grains in the ultramylonitic layers show a weak crystallographic preferred orientation (Fig. 4a; max. $J$ index 1.4) with a $c$ axis distribution around the periphery of the pole figure containing a point maximum orientated oblique to the foliation plane. The poles of $e$ planes (01-18) show a similar preferred orientation to that of the $c$ axis distribution. Both $a$ axes $\langle 11-20\rangle$ and poles of $m$ planes $\{10-10\}$ are preferentially orientated in a slightly oblique girdle with respect to the foliation plane, orientated almost perpendicular to the $c$ axis point maximum, showing one point maximum in the centre of the pole figure. The poles of $r$ planes $\{10-14\}$ show four very weakly defined point maxima of which one is almost perpendicular to the foliation plane.

Misorientation-angle distributions (Fig. 4b) of neighbourpair and random-pair grains are similar and track the calculated curve of an ideal random misorientation-angle distribution calculated for trigonal crystal symmetry reasonably. Minor variation in curves is visible for misorientations up to $40^{\circ}$ where neighbour-pair grains constitute a higher pop- ulation fraction and for misorientations higher than $80^{\circ}$ for which the fraction of random-pair grains is higher.

Almost no internal misorientation is visible within the grains displayed as a misorientation deviation map wherein the misorientation over each grain with respect to its average misorientation is plotted (Fig. 4c). Small, $(<10 \mu \mathrm{m})$ almost equigranular grains appear to be strain free or have a uniform strain distribution. Misorientations up to $13^{\circ}$, subgrains and bulges with approximately the same size as the ultrafine-grained (UFG) calcite are observed only within coarser grains $(>10 \mu \mathrm{m})$.

\subsection{Grain surface microstructure}

Secondary electron images (SEIs) of broken specimens show that the marble preferentially fractures along grain boundaries with well-pronounced crystal faces (Fig. 5a, b); only grains larger than $15 \mu \mathrm{m}$ break along cleavage planes during sample preparation. Similar to both SEIs of thin sections (4.1) and TEM observations (4.3), cavities of varying sizes up to $1 \mu \mathrm{m}$ across are preferentially located at grain triple junctions (Fig. 5c, d). Locally, grain boundary openings following more than one grain occur as thin intergranular cracks (Fig. 5a) and might be interpreted as preparation artefacts. Small ledges at grain boundaries are often located close to a cavity or grain boundary opening (Fig. 5a, c). Small, similarly orientated cavities are concentrated at grain boundaries (Fig. 5f), as also observed in SEIs of thin sections. In general, the grain surfaces are very smooth; only rarely do fine pores occur. These pores vary slightly in size but typically have a similar oval shape (Fig. 5e). Locally, grain boundaries 
(a)
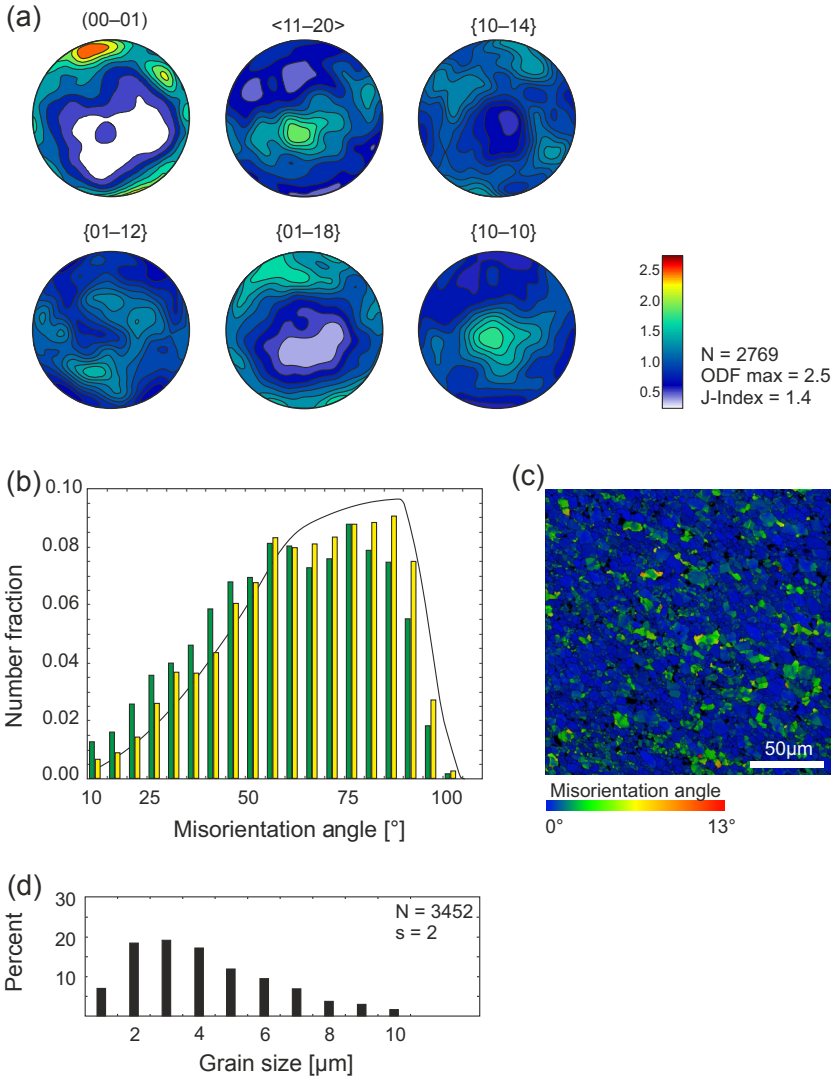

Figure 4. (a) Stereographic equal area lower hemisphere projection of $c(0001)$ and $-a<11-20>$ axes and poles of $r\{10-41\}$, $f\{0-12\}, e\{01-18\}$ and $m\{10-10\}$ planes. $N$ represents the number of analysed grains. Texture strength is represented by the intensity of the orientation distribution function (ODF); additionally, information on the $J$ index is given. (b) Histogram showing the misorientation-angle distribution of neighbour-pair (green) and random-pair grains (yellow). The curve represents the calculated theoretical curve for a perfectly random misorientation-angle distribution for trigonal crystal symmetry. (c) Orientation deviation map representing the misorientation over each grain with respect to its average misorientation. (d) Grain-size histogram of UFG. $N$ denotes the total number of analysed grains; $s$ denotes standard deviation.

are slightly curved and appear to flow around neighbouring grains (Fig. 5e).

\subsection{Defect microstructure (TEM)}

A heterogeneous grain microstructure occurs across the optical transition zone (Fig. 6a, b). These variations correlate with distinctive defect substructures observed by TEM. Coarser calcite grains $(>10 \mu \mathrm{m})$ contain a high number of low-angle subgrain boundaries defined by well-organized dislocations walls, as well as free dislocations (Fig. 6c, d). Smaller grains $(<5 \mu \mathrm{m})$ located in the transition zone are almost free of dislocations and have a sharp, convex high-angle
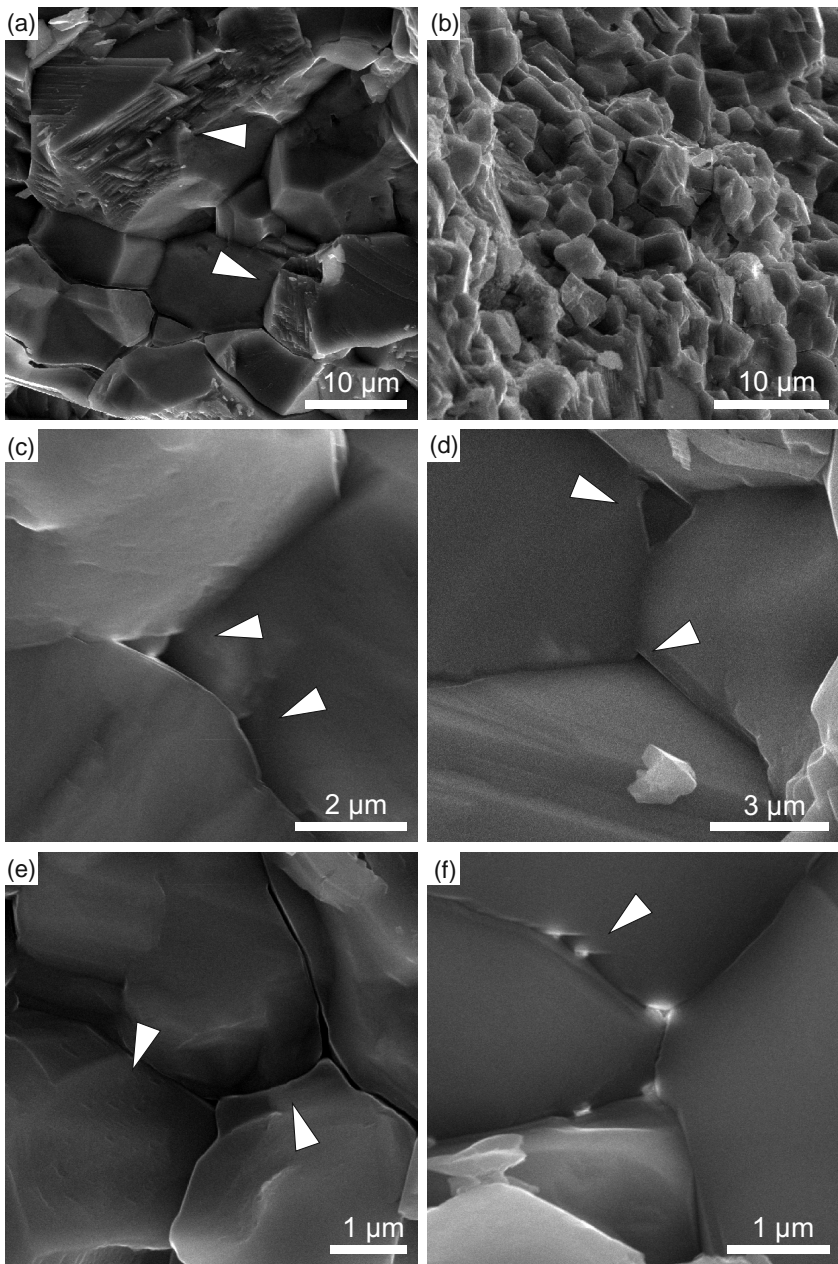

Figure 5. SE images of broken specimens. (a) Slightly coarser grained area showing how grains larger than $15 \mu \mathrm{m}$ break along the cleavage, while small grains break along their boundaries. (b) Fine equigranular calcite grains showing crystal faces. (c) Small cavities at grain triple junctions and grain boundaries next to ledges. (d) Cavities at grain triple junctions. (e) Grain boundary openings appearing to be closed by flowing grains. Note the small pores on the grain surface of the left grain. (f) Small cavities with the same orientation piling up at the grain boundary.

grain boundary towards the dislocation-rich coarser calcite grains (Fig. 6b-d). Locally, small grains form pronounced crystal faces (Fig. 6d).

In contrast to the transition zone, small grains within the fine-grained ultramylonite contain abundant free dislocations (Fig. 7). Dislocation multiplication by Frank-Read sources is observed throughout the ultramylonite at grain boundaries (Fig. 7a); likewise, glide dislocations are commonly concentrated or pinned at grain boundaries (Fig. 7b). Glide dislocations are well developed on $f$-type planes (Fig. 7c, d). All grains within the fine-grained ultramylonite, independent of size, have a high dislocation density with an average of $5 \times 10^{13} \mathrm{~m}^{-2}$ (Fig. 7e). In contrast to the coarser grained cal- 

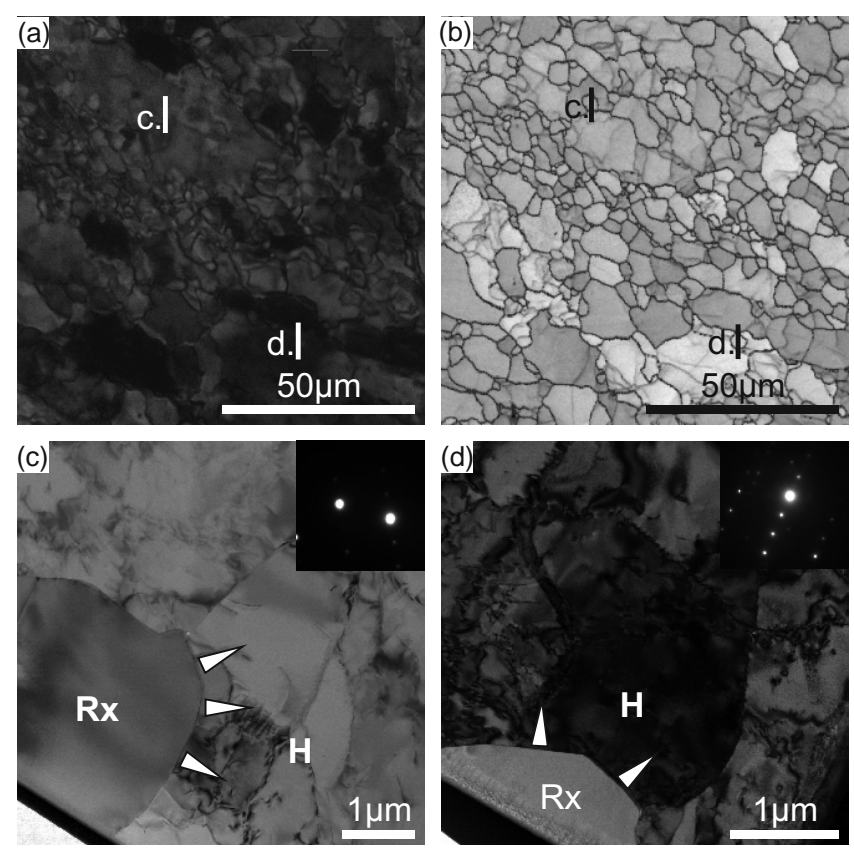

Figure 6. (a) Optical micrograph (crossed polarizer) showing the transition zone between coarse- and fine-grained ultramylonite. Panels (c) and (d) represent the locality of focused ion beam (FIB) foils. (b) Electron backscatter diffraction (EBSD) map showing the transition zone between coarse- and fine-grained ultramylonite. High-angle boundaries $\left(>15^{\circ}\right)$ are plotted in blue. Panels (c) and (d) show the locality of FIB foils. Note that the foils represent a profile across fine-grained ultramylonitic grains adjacent to a coarse grain. (c) Dislocation-rich host $(H)$ calcite and dislocationfree recrystallized $\left(R_{x}\right)$ grains. Bulging (migration) direction of recrystallizing grain boundary shown by arrows. TEM bright field; $g=02-2-1$. (d) Dislocation-free calcite grain $(\mathrm{Rx})$ adjacent to coarser grains with a high density of free dislocations and dislocations arranged to low-angle grain boundaries. Bright field TEM; $B \sim[2-201]$ in host grain.

cite, the fine-grained ultramylonitic calcite only rarely exhibits well-formed subgrain boundaries. Instead, dislocation networks define small cells of around $200 \mathrm{~nm}$ (Fig. 7f) in size, partly showing a hexagonal shape. Voids are conspicuous within the ultramylonite at grain triple junctions and as arrays along grain boundaries consistent with SEM observations.

\section{Analysis and discussion}

The Syros ultramylonite exhibits a distinctive assemblage of attributes that require an internally consistent explanation. These important microstructural components are (1) extreme grain size reduction at low homologous temperature; (2) high-strain deformation of the resultant UFG calcite; (3) extensive dislocation glide with minimal recovery as a component of the high strain, concomitant with (4), the cre-
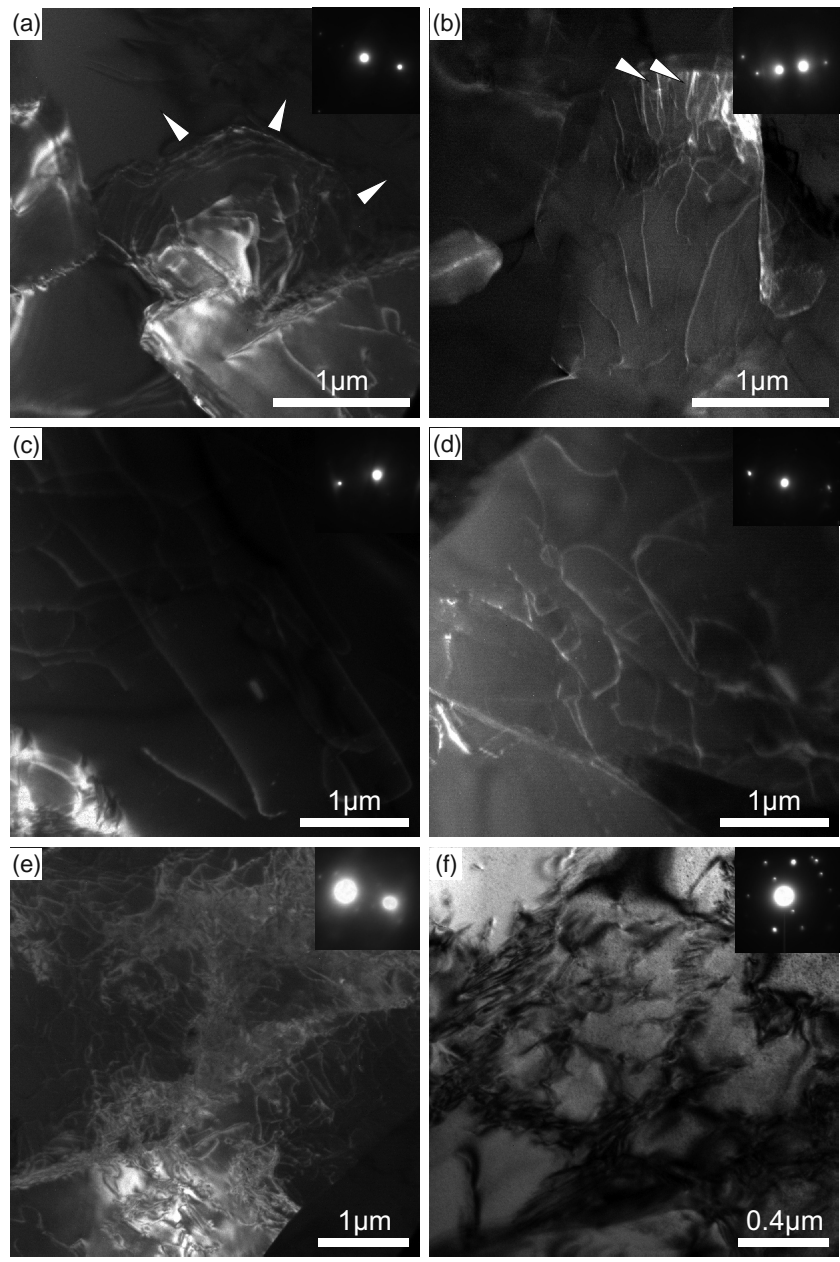

Figure 7. Typical TEM dislocation structures within the finegrained ultramylonite. (a) Frank-Read source pinned at a grain boundary with multiplication and propagation of dislocation loops outward (arrows) on a $f\{01-12\}$ glide plane; TEM dark field, $g=12-35$. (b) Glide dislocations pinned at a grain boundary; TEM bright field, $g=0-114$. (c) Extended glide dislocations. TEM dark field; $g=31-42$. (d) Dislocation gliding in f-plane with notable dipole (arrow). TEM dark field; $g=1-32-4$. (e) Typical high dislocation density in UFG calcite. TEM dark field; $g=30-33$. (f) Cells (200 nm structure) defined by dislocation arrays interpreted to be related to network-assisted recovery at low homologous temperature. TEM bright field; $B \sim[2-1-10] g=0-114$.

ation of a primary CPO in the UFG calcite; and (5) the development of nanopores. It is argued that these collectively reflect intense plastic deformation transitioning to GSS deformation comprising simultaneous operation of independent GBS and dislocation activity.

\subsection{Grain size reduction}

Extreme reduction in grain size can occur by brittle/frictional deformation (Blenkinsop, 1991; Mair and Abe, 2011) or solid-state dynamic recrystallization (White, 1973, 1977, 
1982; Poirier and Nicolas, 1975; Etheridge and Wilkie, 1979; Sakai et al., 2014 amongst others). Although brittle fractures commonly act as loci for subsequent ductile displacement (e.g. Pennacchioni and Mancktlow, 2007) there is no indication of this behaviour during development of the ultramylonite. The microstructural evolution clearly demonstrates that dynamic recrystallization during intense plastic deformation is the grain-size-reducing mechanism (Rogowitz et al., 2014). Small calcite grains within the transition zone between the two ultramylonitic layers of contrasting grain size have low dislocation densities compared to adjacent coarser grains (Fig. 6c, d). The convex curvature of the grain boundary towards highly dislocated grains indicates grain boundary migration from the small grain towards the coarser grain indicative of bulging recrystallization, where the driving force for grain boundary movement is the contrast in internal strain energy between grains (Takeuchi and Argon, 1976; White and White, 1980; Sakai and Jonas, 1984; Platt and Behr, 2011). During grain boundary migration, the dislocation-rich volume is reorganized (consumed), resulting in a decrease in elastic strain energy. Dislocation reorganization into a new grain boundary (migration) is not inconsistent with concomitant increase in misorientation (rotation) between grains. The final "new" grain boundary will reflect the combined effect of dislocation incorporation and annihilation in the net lower energy defect configuration. Minor subgrains and bulges within coarser left-over grains in the UFG ultramylonite indicate continuous recrystallization of grains too big for sliding.

\subsection{Dislocation activity, texture development and GBS}

The ultra-fine-grained, recrystallized equigranular microstructure of the Syros ultramylonite is characteristic of materials exhibiting GSS deformation (Boullier and Guéguen, 1975; Schmid, 1976; Rutter, 1994). GSS flow results from the decreased diffusional mass transport distance through small grains (Nabarro-Herring creep), the enhanced diffusion rates through the integrated defects that are grain boundaries (Coble creep) and the reduced effective viscosity of grain boundaries by dislocation movements that is represented as independent GBS (Gifkins, 1976). Overall GBS reflects the role that grain boundaries play in accommodating very large macroscopic strains (Raj and Ashby, 1971; Ashby and Verrall, 1973; Gifkins, 1976; Langdon, 2009 and references therein). GSS flow has, in most materials, including rocks, been linked to a combination of sustained small grain size over large strains, low differential stress and homologous temperatures high enough to support diffusional accommodation of grain rearrangements during GBS (e.g. Ashby and Verrall, 1973; Boullier and Guéguen, 1975; Schmid, 1976). Only the small equant grain size and high strain are characteristics of the Syros ultramylonite. The primary CPO formed in the ultramylonite (Fig. 4a) contradicts the common anticipation that GSS deformation mechanisms will result in a randomization or loss in CPO intensity (Zhang et al., 1994; Bestmann and Prior, 2003; Storey and Prior, 2005).

A primary texture could, in principle, develop in one of three ways during GSS flow. Deformation within the GSS creep field can be associated with grain growth due to diffusion processes or surface-energy-driven coarsening (Aktinson, 1988). In a non-isotropic stress field the growth of grains during deformation will be stress directed and can result in a weak CPO (Schmid et al., 1977; Bons and den Brok, 2000). The limited evidence for abundant grain growth makes stress-directed growth a rather unlikely explanation for the observed texture. The high deformation stress and strain rate conditions at relatively low temperatures suppress any substantive crystal growth in the UFG ultramylonite, with cyclic grain size reduction, maintaining the grain size range between 10 and $1 \mu \mathrm{m}$.

A second explanation for the case of polyphase materials deformed by diffusion (Coble) creep in combination with GBS is a CPO developing by reorientation of grains towards a preferred alignment for interface reactions (Heidelbach et al., 2000; Sundberg and Cooper, 2008). Deformation by GBS would be consistent with the observed random misorientation-angle distribution (Fig. 5b), indicating that no relation between neighbouring grains exists, a typical pattern being observed for grains deformed by GBS (Wheeler et al., 2001; Bestmann and Prior, 2003). However, the ultramylonitic marble is essentially pure with only minor amounts of quartz, dolomite and mica being stable over a wide range of $P-T$ conditions along the $P-T$ path of Syros (Rogowitz et al., 2015), making any mineral reactions almost impossible. Also the smooth surfaces of calcite grains argue against secondary crystal growth and mineral reactions, and the dislocation density argues against dominant diffusion creep. This explanation can be dismissed.

The third, and favoured explanation suggests the invoking of concomitant dislocation activity and GBS. Notwithstanding that much of the discussion of GBS in rocks has focussed on diffusional accommodation in the style of Ashby and Verrall (1973), there is, in principle, no preclusion of dislocation activity during GBS (Crossman and Ashby, 1975; Gifkins, 1976). At the same time, intracrystalline deformation by dislocation glide remains the most feasible explanation for $\mathrm{CPO}$ development.

There is long-standing evidence of rock deformation experiments that exhibit mixed dislocation activity and GBS. Schmid et al. (1977) deformed Solnhofen limestone at temperatures above $800^{\circ} \mathrm{C}$ and Rutter et al. (1994); likewise, they deformed fine-grained calcite aggregates at temperatures around $700{ }^{\circ} \mathrm{C}$, for which deformation of relict coarser grains by dislocation creep simultaneously with predominant GBS was observed. Nevertheless, the latter are examples of dislocation activity of coarse grains within a fine matrix, not deformation of the matrix itself. The introduction of highstrain torsion experiments has resolved the apparent absence of characteristic microstructures and constitutive behaviour 
interpreted as dislocation-accommodated GBS (Hirth and Kohlstedt, 2003; Hansen et al. 2011; Kushnir et al., 2015). Experimental studies exhibiting anomalous stress and grain size exponents of 2 (Walker et al., 1990; Kushnir et al. 2015) that do not correspond to ideal models of dislocation (Weertman, 1957; Evans and Knowles, 1978) or diffusion creep (Coble, 1963; Ashby and Verrall, 1973), are, nevertheless, consistent with models of dislocation-accommodated GBS (Gifkins, 1976).

The sequence of microstructural development observed in this study constitutes mylonitization of the calcite marble, with grain size reduction by dynamic recrystallization producing relatively strain-free small grains as observed within the transition zone from coarse- to fine-grained ultramylonite (Fig. 6). Progressive deformation of fine-grained ultramylonitic layers results in extensive dislocation activity within the grains, including dislocation multiplication (Frank-Read sources) and development of high dislocation densities (Fig. 7), a microstructural combination that is distinct from the transition zone and demonstrates that the dislocations are not simply a late overprint pulse that introduced dislocations in all part of the structure. Rather, a substantive amount of intracrystalline strain must be accommodated by crystal plasticity within the fine-grained ultramylonite, which at the same time has attributes of GBS.

Minor low-angle boundaries in the fine-grained calcite are consistent with negligible thermally activated recovery associated dislocation creep. Nevertheless, the localization in the ultramylonite requires intense strain-softening. The dislocation networks and $200 \mathrm{~nm}$ cells observed in the ultramylonite are common to calcite deformed at low temperature (Kennedy and White, 2001; Vitale et al, 2007; Molli et al., 2011). The edge character of most network dislocations (picket fence arrays) and crystallographic alignment of cell walls is indicative of glide-mediated network formation that fills the role of climb-mediated recovery at low homologous temperature. Also, cross-slip has been argued to be active under these conditions (De Bresser and Spiers, 1990), enabling screw dislocations to overcome barriers to glide. The combined effects are to enhance strain accommodation and provide sufficient recovery to support continued ductile deformation. A substantive contribution of GBS in combination with the latter can explain the observed strain softening.

How can simultaneous dislocation activity and independent GBS be reconciled? As noted, such behaviour is not precluded by models of material behaviour, particularly that on which the core-and-mantle model of deformation (Gifkins, 1976), a central theme in geological deformation, is based. In the latter, the cores of grains act in a largely independent manner from grain mantles where dislocation densities are typically higher, as observed in our study. Within the grain mantles, dislocation motion and grain-boundary-scale deformation accommodates relative grain boundary displacements. Whereas the ensuing rotation and displacement of grains will change the crystal orientation relative to the pre- ferred kinematically favoured orientation, there will be a concomitant impetus for reorientation by continued dislocation glide toward formation of a CPO; randomization of the fabric (controlled within grain mantles) is countered by simultaneous glide throughout the grain. The competition between GBS and glide would require continual change in the critical resolved shear stress on specific crystal planes, leading to the activation of different slip systems that would explain the various observed orientations (Fig. 7). The latter behaviour may require minerals with a sufficient number of alternate slip systems such as that provided by calcite.

\subsection{Origin of cavities and pores}

The process of cavitation remains poorly understood despite the common observation of pores and cavities. Proposed mechanisms for the nucleation of cavities in polycrystalline material include vacancy condensation in a high stress region, the presence of second particles, dislocation pile-up at grain boundaries and GBS (Kassner and Hayes, 2003; Ovid'ko and Sheinerman, 2006; Fusseis et al., 2009; Rybacki et al., 2010). The preferential location of grain boundary openings orientated at a low angle to the shortening direction has already been observed by others in fine-grained polycrystalline material (Ree, 1994; Mancktelow et al., 1998) and has been associated with the activity of GBS. Shape and location of cavities within the fine-grained ultramylonite is very similar to cavities described by Ree (1994) and Ovid'ko et al. (2011) that result from grain neighbour switching during GBS. Opening of cavities occurs parallel to the shortening direction that are during further deformation partly closed due to further sliding of the grains, resulting in a small cavity at grain triple junctions. Therefore, the observed grain boundary openings and cavities at four-grain and triple junctions (Figs. 3a-d, 5) are most likely related to GBS. Dislocation glide, as described in Sect. 5.1, is able to close cavities by plastic deformation (Fig. 5e) while at the same time opening new cavities at a different locality, all of which contributes to the accommodation of GBS.

Contrasting the latter, small pores located on grain surfaces (Fig. 5e) are probably the result of minor grain boundary fluids or fluid-filled pores (Mancktelow et al., 1998). The observed small cavities having the same orientation and piling up at grain boundaries (Figs. 3g, h; 5f) might be interpreted as Zener-Stroh cracks, being the result of stress concentration due to dislocation pile-up at grain boundaries (Stroh, 1954, 1955; Fan and Xiao, 1997). Due to movement of edge dislocations on the same slip plane, the uniform orientation of cracks can be explained. Another possible explanation is stress concentration at obstacles or ledges at grain boundaries. Such features can result in stress concentration during grain sliding and lead to microcracking (Chan et al., 1986). 


\subsection{Differential stress determination}

To test whether our interpretation of dislocation activity synchronous with GBS resides in its compatibility with the predicted rheological response, differential stress has been estimated using dislocation density and recrystallized grain size. The experimental calibration of De Bresser (1996), linking flow stress and dislocation density, has been used to estimate flow stress conditions $\sigma$. Flow stresses were calculated using dislocation densities $\rho$ calculated for maximum, minimum and average specimen thickness:

$\sigma=10^{-6.21} \rho^{0.62}$.

Although this calibration is based on results from single crystals, it is assumed to fit for polycrystalline material deformed at higher differential stresses (> $40 \mathrm{MPa}$ ). The calculated differential stress results in values ranging between 133 and $260 \mathrm{MPa}$ with an average of $197 \mathrm{MPa}$ (Table S1). Differential stress, calculated with the palaeopiezometer, linking recrystallized grain size and differential stresses (Schmid et al., 1980), results in slightly lower stresses of $170 \mathrm{MPa}$. The similarity of stresses calculated using both grain-size-dependent and dislocation-density-dependent calibrations is an argument for minimal post-deformation annealing in the ultramylonitic calcite. It is important to note that all calculated differential stresses lie below the threshold for brittle deformation as determined by the Byerlee law (Byerlee, 1978) for inferred confining pressure conditions of 200 and $400 \mathrm{MPa}$, consistent with the microstructural evidence that the deformation was plastic. Likewise, the high stress estimates are consistent with the observed extent of dislocation glide and inference of cross-slip as an accommodation process.

The deformation behaviour and strain rates predicted for the calculated stresses were examined by constructing a deformation mechanism map for calcite at $300{ }^{\circ} \mathrm{C}$ using calcite flow laws of Herwegh et al. (2003) as an approximation for general GSS behaviour and Renner et al. (2002) for dislocation creep. The mode grain size, when plotted with respect to the corresponding differential stress range, calculated by the palaeopiezometer and dislocation density (Fig. 8), indicates strain rates of $10^{-9}-10^{-10} \mathrm{~s}^{-1}$. The mode grain size plots close to the field boundary between GSS and grainsize-insensitive (GSI) creep (De Bresser et al., 1998, 2001), which is inferred to represent the balancing stable grain size between grain growth active during GSS creep and grain size reduction during GSI creep. Nevertheless the observed grain size range of 1 to $10 \mu \mathrm{m}$ implies grain size reduction to sizes smaller than predicted by the field boundary hypothesis. The small grain size fraction can result from suppression of recrystallized nuclei growth during GBS, combined with slow growth kinetics, while larger grains might be relicts. The existence of the fine-grained ultramylonite close to the field boundary is a further strong argument for the mutual occurrence of GBS within the GSS creep field and dislocation activity.

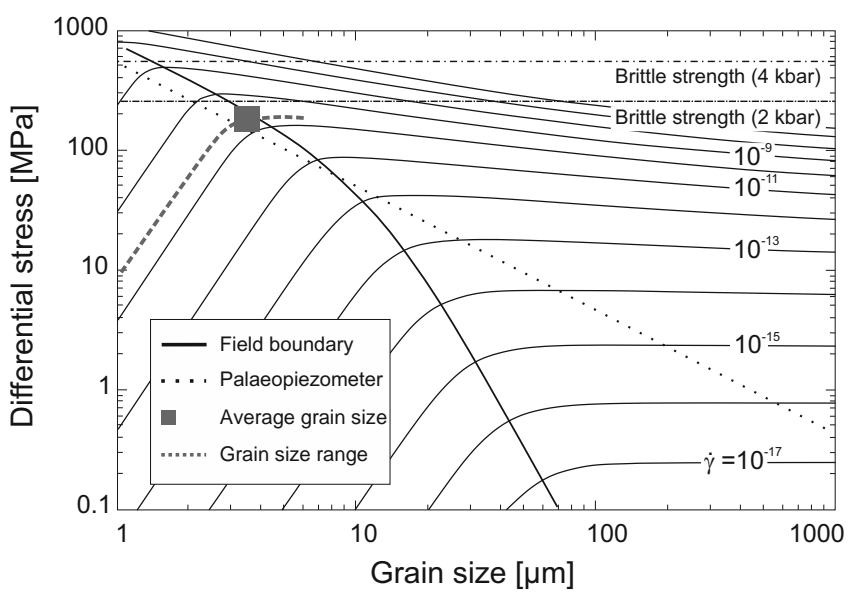

Figure 8. Deformation mechanism map for calcite at $300^{\circ} \mathrm{C}$ in the differential stress versus grain size space. Flow laws used are by Renner et al. (2002) for the dislocation creep field and Herwegh et al. (2003) for grain size sensitive creep. Additionally, the palaeopiezometer (Schmid et al., 1980), the field boundary after De Bresser et al. (1998, 2001) and the brittle strength (Byerlee, 1978) are plotted. The rectangle represents the average grain size.

\section{Conclusions}

Detailed microstructure analysis of an ultramylonitic calcite layer has generated a self-consistent interpretation on shear deformation, resulting in major weakening at low temperatures and high strain rates. The processes observed may be generally applicable to crustal deformation.

1. A highly strained $(\gamma>80)$ calcite ultramylonite is formed by dynamic recrystallization of mylonite grains dominantly by bulging, resulting in small, strain-free grains.

2. The reduction in grain size enables simultaneous deformation by GBS and dislocation activity. Networkassisted dislocation movement and cross-slip aid in lowtemperature recovery of the deforming calcite, given the inadequacy of thermal-induced recovery (climb) to reduce strain hardening effects.

3. Stresses calculated by grain-size-dependent and dislocation-density-dependent calibrations give similar estimates on the order of $180 \mathrm{MPa}$. The consistency of the methods implies that post-deformational annealing was minimal.

4. Strain rates on the order of $10^{-9}-10^{-10} \mathrm{~s}^{-1}$ are predicted for the fine-grained ultramylonite. The high stress and fast strain rate response at low temperatures and dry conditions in a stable mineral paragenesis requires dislocation motion to be the principal mechanism accommodating strain compatibility between displacing grains. 
5. The switch from dislocation creep to simultaneous activation of GBS and dislocation activity results in extreme strain softening and can be an important strain localization process in calcite rocks, even at high strain rate $\left(\sim 10^{-9} \mathrm{~s}^{-1}\right)$ and low temperature $\left(300^{\circ} \mathrm{C}\right)$, where brittle deformation could be anticipated.

\section{The Supplement related to this article is available online at doi:10.5194/se-7-355-2016-supplement.}

Acknowledgements. We thank the University of Vienna (grant number IK543002) for supporting the doctoral school DOGMA, the Austrian Science Fund (FWF): I471-N19 and the Natural Sciences and Engineering Research Council of Canada for a Discovery Grant (Fracture, Friction and Flow). We would like to thank Gerlinde Habler for FIB foil preparation and the University of New Brunswick Microscopy and Microanalysis Facility, particularly Louise Weaver, for support during TEM work. Many thanks to Luiz Morales, Luca Menegon and Benjamin Huet for valuable discussions. Detailed comments by the anonymous reviewer, Hans De Bresser and Michael Stipp are gratefully appreciated and helped a lot to improve the manuscript.

Edited by: M. Stipp

\section{References}

Ashby, M. F. and Verrall, R. A.: Diffusion-accommodated flow and superplasticity, Acta Metall., 21, 149-163, 1973.

Atkinson, H. V.: Theories of normal grain growth in pure single phase systems, Acta Metall., 36, 469-491, 1988.

Bachmann, F., Hielscher, R., and Schaeben, H.: Texture Analysis with MTEX - Free and Open Source Software Toolbox, Sol. St. Phen., 160, 63-68, 2010.

Barreiro, J. G., Lonardelli, I., Wenk, H. R., Dresen, G., Rybacki, E., Ren, Y., and Tomé, C. N.: Preferred orientation of anorthite deformed experimentally in Newtonian creep, Earth Planet. Sci. Lett., 264, 188-207, 2007.

Bestmann, M. and Prior, D. J.: Intragranular dynamic recrystallization in naturally deformed calcite marble: diffusion accommodated grain boundary sliding as a result of subgrain rotation recrystallization, J. Struct. Geol., 25, 1597-1613, 2003.

Blenkinsop, T. G.: Cataclasis and Processes of Particle Size Reduction, Pageoph, 136, 59-86, 1991.

Bons, P. D. and den Brok, B.: Crystallographic preferred orientation development by dissolution-precipitation creep, J. Struct. Geol., 22, 1713-1722, 2000.

Boullier, A. M. and Guéguen, Y.: SP-mylonites: Origin of some mylonites by superplastic flow, Contrib. Mineral. Petr., 50, 93-104, 1975.

Bunge, H. J.: Texture Analysis in Materials Science: Mathematical Models, Butterworths, London, 1982.

Byerlee, J. D.: Friction of rock, Pure Appl. Geophys., 116, 615-626, 1978.
Chan, K. S., Page, R. A., and Lankford, J.: Cavity nucleation at grain boundary ledges, Acta Metall., 34, 2361-2370, 1986.

Coble, R. L.: A model for boundary controlled creep in polycrystalline materials, J. Appl. Phys., 34, 1679-1682, 1963.

Crossmanm F. W. and Ashby, M. F.: The non-uniform flow of polycrystals by grain boundary sliding accommodated by power-law creep, Acta Metall., 23, 425-440, 1975.

De Bresser, J. H. P.: Steady state dislocation densities in experimentally deformed calcite materials: Single crystal versus polycrystals, J. Geophys. Res., 101, 189-201, 1996.

De Bresser, J. H. P. and Spiers, C. J.: High temperature deformation of calcite single crystals by $\mathrm{r}+$ and $\mathrm{f}+$ slip, Deformation Mechanisms, Rheology and Tectonics, Geological Society, London, Special Publications, 54, 285-298, 1990.

De Bresser, J. H. P., Peach, C. J., Reijs, J. P. J., and Spiers, C. J.: On dynamic recrystallization during solid state flow: Effects of stress and temperature, Geophys. Res. Lett., 25, 3457-3460, 1998.

De Bresser, J. H. P., Ter Heege, J., and Spiers, C.: Grain size reduction by dynamic recrystallization: Can it result in major rheological weakening?, Int. J. Earth Sci., 90, 28-45, 2001.

Etheridge, M. A. and Wilkie, J. C.: Grain size reduction, grain boundary sliding and flow strength of mylonites, Tectonophysics, 58, 159-178, 1979.

Evans, H. E. and Knowles, G.: Dislocation creep in non-metallic materials, Acta Mater., 25, 963-975, 1978.

Fan, H. and Xiao, Z. M.: A Zener-Stroh Crack near an interface, Int. J. Sol. Struct., 34, 2829-2842, 1997.

Fusseis, F., Regenauer-Lieb, K., Liu, J., Hugh, R. M., and De Carlo, F.: Creep cavitation can establish a dynamic granular fluid pump in ductile shear zones, Nature, 459, 974-977, 2009.

Gifkins, R. C.: Grain-boundary sliding and its accommodation during creep and superplasticity, Metall. Trans. A, 7, 1225-1232, 1976.

Hansen, L. N., Zimmerman, M. E., and Kohlstedt, D. L.: Grain boundary sliding in San Carlos olivine: flow law parameters and crystallographic preferred orientation, J. Geophys. Res., 116, B08201, doi:10.1029/2011JB00220, 2011.

Heidelbach, F., Post, A., and Tullis, J.: Crystallographic preferred orientation in albite samples deformed experimentally by dislocation and solution precipitation creep, J. Struct. Geol., 22, 1649-1661, 2000.

Herwegh, M., Xiao, X., and Evans, B.: The effect of dissolved magnesium on diffusion creep in calcite, Earth Planet. Sci. Lett., 212, 457-470, 2003.

Hirth, G. and Kohlstedt, D. L.: Rheology of the upper mantle and the mantle wedge: a view from the experimentalists, in: Inside the Subduction Factory, Geophys. Monogr., 138, 83-105, 2003.

Jolivet, L. and Brun, J. P.: Cenozoic geodynamic evolution of the Aegean, Int. J. Earth Sci., 99, 109-138, 2010.

Kassner, M. E. and Hayes, T. A.: Creep cavitation in metals, Int. J. Plasticity, 19, 1715-1748, 2003.

Keiter, M., Piepjohn, K., Ballhaus, C., Lagos, M., and Bode, M.: Structural development of high-pressure metamorphic rocks on Syros island (Cyclades, Greece), J. Struct. Geol., 26, 1433-1445, 2004.

Kennedy, L. A. and White, J. C.: Low-temperature recrystallization in calcite: Mechanisms and consequences, Geology, 29, 10271030, 2001. 
Kushnir, A. R. L., Kennedy, L. A., Misra, S., Benson, P., and White, J. C.: the mechanical and microstructural behaviour of calcitedolomite composites: An experimental investigation, J. Struct. Geol., 70, 200-216, 2015.

Langdon, T. G.: Seventy-five years of superplasticity: historic developments and new opportunities, J. Mater. Sci., 44, 5998-6010, 2009.

Mackenzie, J. K. and Thompson, M. J.: Some statistics associated with the random disorientation of cubes, Biometrika, 44, 205210, 1957.

Mair, K. and Abe, S.: Breaking Up: Comminution Mechanisms in Sheared Simulated Fault Gouge, Pure Appl. Geophys., 168, 2277-2288, 2011.

Mancktelow, N. S., Grujic, D., and Johnson, E. L.: An SEM study of porosity and grain boundary microstructure in quartz mylonites, Simplon Fault Zone, Contrib. Mineral. Petr., 131, 71-85, 1998.

Menegon, L., Stünitz, H., Nasipuri, P., Heilbronner, R., and Svahnberg, H.: Transition from fracturing to viscous flow in granulite facies perthitic feldspar (Lofoten, Norway), J. Struct. Geol., 48, 95-112, 2013.

Molli, G., White, J. C., Kennedy, L., and Taini, V.: Low-temperature deformation of limestone, Isola Palmaria, northern Apennine, Italy - The role of primary textures, precursory veins and intracrystalline deformation in localization, J. Struct. Geol., 33, 255-270, 2011.

Ovid'ko, I. A. and Sheinerman, A. G.: Nanovoid generation due to intergrain sliding in nanocrystalline materials, Philos. Mag., 86, 3487-3502, 2006.

Ovid'ko, I. A., Sheinerman, A. G., and Skiba, N. V.: Elongated nanoscale voids at deformed special grain boundary structures in nanocrystalline materials, Acta Mater., 59, 678-685, 2011.

Papanikolaou, D. J.: Tectonic evolution of the Cycladic Blueschist Belt (Aegean Sea, Greece), edited by: Helgeson, H. C., Chemical Transport in Metasomatic Processes, 429-450, 1987.

Pennacchioni, G. and Mancktelow, N. S.: Nucleation and initial growth of a shear zone network within compositionally and structurally heterogeneous granitoids under amphibolite facies conditions, J. Struct. Geol., 29, 1757-1780, 2007.

Philippon, M., Brun, J. P., and Gueydan, F.: Tectonics of the Syros blueschists (Cyclades, Greece): From subduction to Aegean extension, Tectonics, 30, TC4001, doi:10.1029/2010TC002810, 2011.

Platt, J. P. and Behr, W. M.: Grainsize evolution in ductile shear zones: Implications for strain localization and the strength of the lithosphere, J. Struct. Geol., 33, 537-550, 2011.

Poirier, J. P and Nicolas, A.: Deformation-induced recrystallization due to progressive misorientation of subgrains, with special reference to mantle peridotites, J. Geol., 83, 707-720, 1975.

Raj, R. and Ashby, M. F.: On grain boundary sliding and diffusional creep, Metall. Trans., 2, 1113-1127, 1971.

Ree, J. H.: Grain boundary sliding and development of grain boundary openings in experimentally deformed octachloropropane, J. Struc. Geol., 16, 403-418, 1994.

Renner, J., Evans, B., and Siddiqi, G.: Dislocation creep of calcite, J. Geophys. Res., 107, ECV6-1-ECV6-16, 2002.

Rogowitz, A., Grasemann, B., Huet, B., and Habler, G.: Strain rate dependent calcite microfabric evolution - An experiment carried out by nature, J. Struct. Geol. Pt. A, 69, 1-17, 2014.
Rogowitz, A., Huet, B, Schneider, D., and Grasemann, B.: Influence of high strain rate deformation on ${ }^{40} \mathrm{Ar} /{ }^{39} \mathrm{Ar}$ mica ages from marble mylonites (Syros, Greece), Lithosphere, 2015.

Rutter, E. H., Casey, M., and Burlini, L.: Preferred crystallographic orientation development during the plastic and superplastic flow of calcite rocks, J. Struct. Geol., 16, 1431-1446, 1994.

Rybacki, E., Wirth, R. and Dresen, G.: Superplasticity and ductile fracture of synthetic feldspar deformed to large strain, J. Geophys. Res., 115, B08209, doi:10.1029/2009JB007203, 2010.

Sakai, T. and Jonas, J. J.: Overview no. 35 Dynamic recrystallization: Mechanical and microstructural considerations, Acta Metall., 32, 189-209, 1984.

Sakai, T., Belyakov, A., Kaibyshev, R., Miura, H., and Jonas, J. J.: Dynamic and post-dynamic recrystallization under hot, cold and severe plastic deformation conditions, Prog. Mater. Sci., 60, 130 207, 2014.

Schmid, S. M.: Rheological evidence for changes in the deformation mechanism of Solnhofen limestone towards low stress, Tectonophvsics, 31, T21-T28, 1976.

Schmid, S. M., Boland, J. N., and Paterson, M. S.: Superplastic flow in fine grained limestone, Tectonophysics, 43, 257-291, 1977.

Schmid, S. M., Paterson, M. S., and Boland, J. N.: High temperature flow and dynamic recrystallization in Carrara marble, Tectonophysics, 65, 245-280, 1980.

Schumacher, J. C., Brady, J. B., Cheney, J. T., and Tonnsen, R. R.: Glaucophane-bearing Marbles on Syros, Greece, J. Petrol., 49, 1667-1686, 2008

Segall, P. and Pollard, D. D.: Joint formation in the granitic rock of the Sierra Nevada, Geol. Soc. Bull., 94, 555-568, 1983.

Storey, C. D. and Prior, D. J.: Plastic deformation and recrystallization of garnet: a mechanism to facilitate diffusion creep, J. Petrol., 46, 2593-2613, 2005.

Stroh, A. N.: The formation of cracks as a result of plastic flow, 1954.

Stroh, A. N.: The formation of cracks in plastic flow II, 1955.

Sundberg, M. and Cooper, R. F.: Crystallographic preferred orientation produced by diffusional creep of harzburgite: Effects of chemical interactions among phases during plastic flow, J. Geophys. Res.-Solid Earth, 113, B12208, doi:10.1029/2008JB005618, 2008.

Takeuchi, S. and Argon, A. S.: Steady-state creep of single phase crystalline material at high temperature, J. Mater. Sci., 11, 1542 1566, 1976.

Trotet, F., Vidal, O., and Jolivet, L.: Exhumation of Syros and Sifnos metamorphic rocks (Cyclades, Greece), New constraints on the P-T paths, Eur. J. Mineral., 13, 901-920, 2001.

Vitale, S., White, J. C., Iannace, A., and Mazzoli, S.: Ductile strain partitioning in micritic limestones, Calabria, Italy: the roles and mechanisms of intracrystalline and intercrystalline deformation, Can. J. Earth Sci., 44, 1587-1602, 2007.

Walker, A. N., Rutter, E. H., and Brodie, K. H.: Experimental study of grain-size sensitive flow of synthetic, hot-pressed calcite rocks, Geological Society, London, Special Publications, 54, 259-284, 1990.

Wang, Z., Zhao, Y., and Kohlstedt, D. L.: Dislocation creep accommodated by grain boundary sliding in dunite, J. Earth Sci., 21, 541-554, 2010.

Weertman, J.: Steady-state creep through glide and climb, J. Appl. Phys., 28, 362-364, 1957. 
Wheeler, J., Prior, D., Jiang, Z., Spiess, R., and Trimby, P.: The petrological significance of misorientations between grains, Contrib. Mineral. Petr., 141, 109-124, 2001.

White, J. C.: Quartz deformation and the recognition of recrystallization regimes in the Flinton Group conglomerates, Ontario, Can. J. Earth Sci., 19, 81-93, 1982.

White, J. C. and White, S. H.: High-voltage transmission electron microscopy of naturally deformed polycrystalline dolomite, Tectonophysics, 66, 35-54, 1980.
White, S.: Syntectonic recrystallization and texture development in quartz, Nature, 244, 276-278, 1973.

White, S.: Geological significance of recovery and recrystallization processes in quartz, Tectonophysics, 39, 143-170, 1977.

Wortel, M. J. R., Goes, S. D. B., and Spakman, W.: Structure and seismicity of the Aegean subduction zone, Terra Nova, 2, 554 562, 1993.

Zhang, Y., Hobbs, B. E., and Jessell, M. W.: The effect of grainboundary sliding on fabric development in polycrystalline aggregates, J. Struct. Geol., 16, 1315-1325, 1994. 